\title{
Insecticidal activity of young and mature leaves essential oil from Eucalyptus globulus Labill. against Tribolium confusum Jacquelin du Val (Coleoptera: Tenebrionidae)
}

\author{
Serafina Russo $^{1^{*}}$, Nora Cabrera ${ }^{2}$, Hugo Chludil ${ }^{1}$, Margarita Yaber-Grass ${ }^{1}$, and Silvia Leicach ${ }^{1}$
}

\begin{abstract}
The confused flour beetle, Tribolium confusum Jaquelin Du Val, 1868, is a common pest insect known for attacking and infesting stored flour and grain. Biodegradable and ecologically natural products such as essential oils are emerging candidates for replacement of usually applied chemical pesticides. This work reported the chemical composition and effects caused by young and mature leaves essential oils (EOs) from Eucalyptus globulus Labill. against T. confusum. For both oils, no significant differences between yields were observed, being 1,8-cineole the main common constituent. Mature leaves extracts were rich in oxygenated mono- and sesquiterpenes, whereas young leaves showed greater content of nonoxygenated compounds. Bioassay was performed using EOs and 1,8-cineole solutions at different concentrations and time intervals. Adult mortality increased according to concentration and exposure time; young leaves extracts exhibited the greater effectiveness, highest mortalities $(31.67 \%)$ at the minor time ( $2 \mathrm{~h})$. At the lowest concentrations, 1,8-cineole solutions and mature leaves EOs did not achieve $100 \%$ mortality even when the bioassay was concluded (12 h), while at major doses no insects were alive. These results suggested that young and mature EOs from E. globulus constitute an alternative natural product to the control of $T$. confusum, since young leaves extracts, rich in monoterpene and sesquiterpene hydrocarbons, may be potential eligible candidates considering their noticeable insecticidal effects at low applied concentrations and short times of exposure.
\end{abstract}

Key words: Essential oil, Eucalyptus globulus, insecticidal properties, Tribolium confusum.

\section{INTRODUCTION}

Cereals and legumes constitute the most important diet component for the majority of people in the world and are usually stored to provide food and feed reserves as well as seed for planting. The presence of pests is a serious on-going problem in stored grains and its derived industry (Pérez Mendoza et al., 2004). Flour beetles of Tribolium genus are important pests of stored substances such as flour, cereals, beans, and manufactured products (Jovanovic et al., 2007; Mediouni Ben Jemâa et al., 2013). In many storage systems, the use of chemical pesticides and fumigants is the most economical and common practice used (Boyer et al., 2012). However, in many countries have also been reported developments of insect strains resistant to pesticides, toxic residues for human consumption, acute and chronic toxicity for workers and adverse effects on the environment (Vinayachandra and Chandrashekar, 2011).

\footnotetext{
${ }^{1}$ Universidad de Buenos Aires, Facultad de Agronomía, Avenida San Martín 4453, 1417, Ciudad Autónoma de Buenos Aires, Argentina. *Corresponding author (srusso@agro.uba.ar).

${ }^{2}$ Universidad Nacional de La Plata, Facultad de Ciencias Naturales y Museo, Paseo del Bosque s/n, 1900 La Plata, Argentina.

Received: 2 December 2014.

Accepted: 21 April 2015.
}

doi:10.4067/S0718-58392015000400015
Studies indicate that essential oils (EOs), plant secondary metabolites, may affect significantly the plant resistance to parasites and microorganisms. The active components are monoterpenes and sesquiterpenes (hydrocarbon and oxygenated terpenoid derivatives), and aliphatic compounds such as alkanes, alkenes, ketones, aldehydes, acids, and alcohols. These compounds are carriers and responsible of the odor of aromatic plants (El-Zemity et al., 2006). They are easily extractable, ecofriendly, biodegradable, possess low or no toxicity against mammals, and are very effective against wide spectrum of insect pests (Batish et al., 2008; Lucia et al., 2012).

Eucalyptus species, belonging to Myrtaceae family, are native to Australia, New Guinea, and Indonesia and they are highly exploited because of its wood and essential oils. Its leaves contain volatile compounds, such as $\alpha$ - and $\beta$-pinene, globulol, terpineol, and 1,8-cineole (CIN), the last one is the predominant monoterpene in the most Eucalyptus species (Lucia et al., 2012). These essential oils have been reported to have antimicrobial, antifungal, antiviral, and insecticidal activities, and even have been demonstrated contact and fumigant insecticidal action against stored product pest and others insects (Mann and Kaufman, 2012). Lee et al. (2004) have studied the fumigant toxicity of 42 species belonging to the Myrtaceae family against storage grain pests (rice weevil Sitophilus oryzae Linnaeus 
(Coleoptera: Curculionidae), red flour beetle Tribolium castaneum (Herbst) (Coleoptera: Tenebrionidae) and lesser grain borer Rhyzopertha dominica (F.) (Coleoptera: Bostrichidae) and determined that the good effectiveness of the essential oils being attributed to their respective CIN content.

Secondary metabolites play an important role in the adaptation of plants to the environment and in overcoming stress conditions. Biotic and abiotic factors may alter plant growth, and the production and composition of secondary metabolites. Also, in a previous work, we describe the effect of drought stress on the EO composition in leaves from E. camaldulensis Dehnh. (Leicach et al., 2010). Another factor that can modify the composition of EOs is ontogenetic stage of plants, so in this paper we compared the percentage of non-oxygenated and oxygenated terpenes in the EO of Eucalyptus globulus from young and adult leaves, and evaluated their insecticidal effect against Tribolium confusum. Botanical insecticides are a sustainable alternative to integrated pest management that could contribute to reduce the use of synthetic insecticides.

\section{MATERIAL AND METHODS}

\section{Essential oils extraction and chemical analysis}

The essential oils extraction was done in fresh young and mature leaves of E. globulus were collected during March 2010 from plants cultivated in Lobería (389'48” S, 5846’53” W), Buenos Aires, Argentina. Essential oils were extracted from freshly collected leaves (150 g) by hydrodistillation using a modified clevenger steam distillation apparatus (Bimar Loga Científica S.R.L., Buenos Aires, Argentina) for 2 h; EO was stored at $-18{ }^{\circ} \mathrm{C}$, in an amber bottle with anhydrous sodium sulfate, until chromatographic analysis. Essential oil content was calculated for each repetition $(n=4)$ and expressed as percentage (v/w, fresh weight).

Gas chromatography (GC) and gas chromatography mass-spectrometry (GC-MS) were performed to evaluate qualitative and quantitative changes composition in EOs.

A volume of $1 \mu \mathrm{L}$ of each sample, dissolved in $\mathrm{CH}_{2} \mathrm{Cl}_{2}$ $(1: 100 \mathrm{v} / \mathrm{v})$, was injected. Relative abundances of EO type components were determined by GC by means of a gas chromatograph (7890A, Agilent Technologies, Santa Clara, California, USA) equipped with a flame ionization detector (FID) using a HP-5 (phenylmethyl siloxane, $30 \mathrm{~m}$ $\times 250 \mu \mathrm{m}$ id $\times 0.25 \mu \mathrm{m}$ ) capillary column. Nitrogen was used as carrier gas and hexadecane as internal standard. Temperature program: Initial temperature $60{ }^{\circ} \mathrm{C}(2 \mathrm{~min})$, $60{ }^{\circ} \mathrm{C}$ to $280{ }^{\circ} \mathrm{C}$ with a ramp of $8{ }^{\circ} \mathrm{C} \mathrm{min}{ }^{-1}$; injector and detector temperature $250{ }^{\circ} \mathrm{C}$. Qualitative identification of the different terpenes was based on a comparison of their retention times to $n$-alkanes, compared to published data and confirmed by co-chromatography with authentic samples. Response factors were determined for standard commercial samples, and as expected when FID is used, they did not differ significantly from unity. Determination of individual compounds was achieved by capillary GC electron impact mass spectrometry (GC-MS; GC-6890, Agilent Technologies) coupled to a mass spectrometer (MSD 5973, Agilent Technologies) with the same characteristics column and identical operating conditions to those previously used for GC. Helium was used as carrier gas, and ionization voltage applied was $70 \mathrm{eV}$, mass range $m / z, 40-400 \mathrm{Da}$.

\section{Insecticidal activity bioassay}

Experiments were performed in the Laboratory of Agricultural Zoology using long-established colonies of $T$. confusum. Adult insects were reared on incubators at wheat flour mixed diet with yeast and corn starch (10:1.5:10; w:w), and kept in darkness at $28 \pm 1{ }^{\circ} \mathrm{C}$ and $60 \%-70 \%$ RH. The insecticidal activity was evaluated by contact method that was conducted using filter paper discs (2-cm diameter pieces, Whatman nr 1). Essential oils were dissolved in acetone (for HPLC, purity $\geq$ $99.0 \%$, Sigma-Aldrich, St. Louis, Minnesota, USA) and applied an amount equal to $0.5,0.75,1.0$, and 1.25 $\mu \mathrm{L} \mathrm{cm}^{-2}$. Each solution was dispensed on the paper surface that was afterwards placed in glass Petri dishes $(9 \mathrm{~cm}$ diameter, $1 \mathrm{~cm}$ high). After $10 \mathrm{~min}$, once the solvent had been evaporated, 10 unsexed adults were deposited into each glass Petri dish and stored in darkness at the same temperature and RH conditions (Caballero-Gallardo et al., 2012). Three replicates were made for each treatment, EO and analytical standard eucalyptol (1,8-cineole, purity $\geq$ 99.0\% Fluka, St. Louis, Minnesota, USA) solutions, at the previously mentioned concentrations. Acetone only was used as control. Adults mortalities were determined after $0.5,2,4,6$, and $12 \mathrm{~h}$ and were considered dead when, prodded with a fine brush (maximum three times), they showed no appendage movement.

\section{Data analysis}

Statistical methods were performed by means of InfoStat/ Professional software, 1.1 version 2002 (Facultad de Ciencias Agropecuarias, Universidad Nacional de Córdoba, Córdoba, Argentina). Tests of normality (Kolmogorov-Smirnov test) and homogeneity of variance (Levene test) were applied in each analysis. Data were evaluated by two-way (treatment/concentration) ANOVA and differences between means were compared using Tukey's test with a 0.05 confidence interval in a completely randomized design. Multivariate analysis of different types of EOs was performed through principal component (Kazi et al., 2008). Principal Component Analysis (PCA) was applied in order to examine the interrelationships between treatments and their EO constituents. Eigenvalues and eigenvectors were calculated using a correlation matrix and PCA biplot was generated using InfoStat/Professional software, 1.1 version. 


\section{RESULTS AND DISCUSSION}

The EO yields are within values found in literature. There were not significant differences in EO yield of young and mature leaves from E. globulus, with percentage values of $1.49 \pm 0.26 \%$ and $1.31 \pm 0.14 \%(\mathrm{v} / \mathrm{w}$, fresh weight), respectively. However, young leaves (YL) had a slightly higher percentage (13.7\%) than mature leaves (ML) in correspondence with literature data ( $\mathrm{Li}$ et al., 1996; Silvestre et al., 1997). Monoterpenes, sesquiterpenes, and the major monoterpene 1,8-cineole (CIN) present in mature and young leaves essential oil from E. globulus are given in Table 1.

There were significant differences in total monoterpene (TM) content in both leaf types (Table 1); TM in ML was approximately $10 \%$ more than in YL. Eucalyptol (CIN) was the main constituent of EOs, anyway its content significantly increased in $\mathrm{ML}(62.11 \%)$ respect to $\mathrm{YL}$ $(52.26 \%)$. Similar results were reported in previous works, however in several studies, CIN content of $E$. globulus oil varied between $18 \%$ and $65 \%$ (Cimanga et al., 2002; McKiernan et al., 2014). This wide variation in composition could be attributed to genetic factors as well as to environmental and agronomic conditions like season, location, and climate; such as soil type or fertility regime, as well as, on extraction procedure (Brooker and Kleinig, 2006; Ebadollahi et al., 2010; Manika et al., 2012).

Oxygenated monoterpenes (OM) showed the major percentage values in ML, corresponding to $74.32 \%$. This percentage was $30.57 \%$ higher than the $\mathrm{OM}$ content in $\mathrm{YL}$ (56.92\%). On the other hand, YL EO showed an important abundance of monoterpene hydrocarbons $(19.15 \%)$, this value was $52.6 \%$ higher than that observed in ML (12.55\%).

With regard to total sesquiterpene content, EO of both YL and ML from E. globulus exhibited similar contents ( $9.4 \%$ and $8.65 \%$, respectively), even though there were no significant differences. Oxygenated sesquiterpenes (OS) demonstrated having a significantly higher percentage in ML EOs (6.00\%) compared to YL (4.73\%), while sesquiterpene hydrocarbon $(\mathrm{SH})$ were found to be much higher than YL oil (4.67\%) respect to ML (2.65\%).

\section{Essential oil principal component analysis}

Through this multivariate analysis, it was possible to extract some variation patterns for EO data. Figure 1

Table 1. Essential oil components in mature and young leaves from Eucalyptus globulus.

\begin{tabular}{lrr}
\hline & Mature leaves & \multicolumn{1}{c}{ Young leaves } \\
\hline Total monoterpenes, \% & $86.87 \pm 0.59 \mathrm{~b}$ & $76.07 \pm 0.40 \mathrm{a}$ \\
Total sesquiterpenes, \% & $8.65 \pm 0.62 \mathrm{a}$ & $9.40 \pm 0.48 \mathrm{a}$ \\
Monoterpene hydrocarbons, \% & $12.55 \pm 0.83 \mathrm{a}$ & $19.15 \pm 1.21 \mathrm{~b}$ \\
Oxygenated monoterpenes, \% & $74.32 \pm 2.51 \mathrm{~b}$ & $56.92 \pm 1.63 \mathrm{a}$ \\
Sesquiterpene hydrocarbons, \% & $2.65 \pm 0.27 \mathrm{a}$ & $4.67 \pm 0.29 \mathrm{~b}$ \\
Oxygenated sesquiterpenes, \% & $6.00 \pm 0.61 \mathrm{~b}$ & $4.73 \pm 0.38 \mathrm{a}$ \\
1,8-cineole, \% & $62.11 \pm 1.23 \mathrm{~b}$ & $52.26 \pm 1.39 \mathrm{a}$ \\
Oil yield, \% (v/w, fresh weight) & $1.31 \pm 0.14 \mathrm{a}$ & $1.49 \pm 0.26 \mathrm{a}$ \\
\hline
\end{tabular}

Different letters in the row indicate significant difference according to Tukey test $(P \leq 0.05)$. Data are given as mean percentage values $(n=4)$.

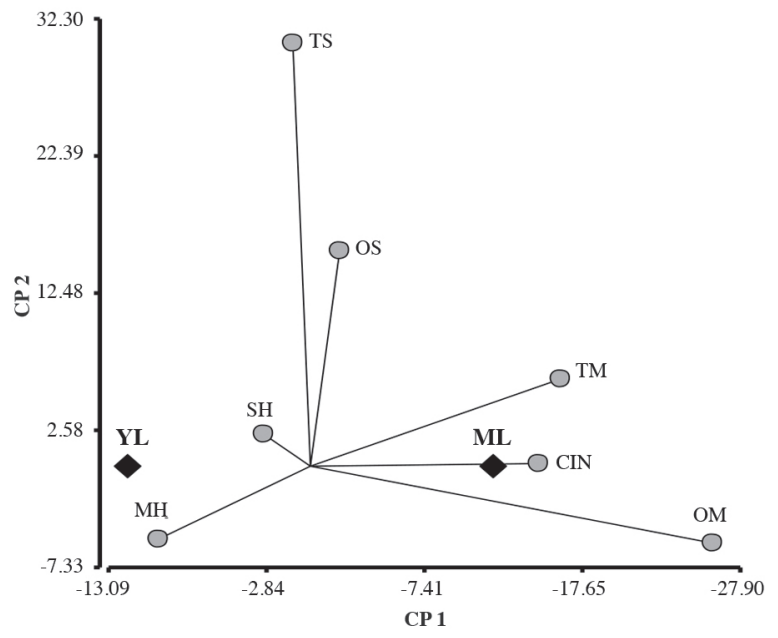

YL: Young leaves, ML: mature leaves, TM: total monoterpenes, TS: total sesquiterpenes, $\mathrm{MH}$ : monoterpene hydrocarbons, OM: oxygenated monoterpenes, SH: sesquiterpene hydrocarbons, OS: oxygenated sesquiterpenes, CIN: 1,8-cineole.

Figure 1. Principal component analysis $(\mathrm{P}<0.05)$ of Eucalyptus globulus essential oil components.

shows distribution of component types of EO on the biplot representation defined by the two first principal components ( $\mathrm{CP} 1$ and $\mathrm{CP} 2$ ), allowing to grouping terpenoids by their abundance.

The first principal component (CP1) accounted for 90\% of total variation, and clearly separated $\mathrm{ML}$ and $\mathrm{YL}$ treatments. Oxygenated monoterpenes $(\mathrm{OM})$ were the most important variable associated to $\mathrm{CP} 1$ exhibiting the highest positive value; followed by TM and CIN, showing that $\mathrm{OM}$ were who most increased their abundances in ML EOs. These results suggest that the high OM content was due to increase in CIN, who was also the major terpene. On the contrary, highest negative values corresponding to $\mathrm{MH}$, followed by lower negative values for SH and TS, strongly associated these components to YL treatment. These observations are in agreement with data showed in Table 1, where MH content in YL EOs was significantly higher than in ML. Some authors, who studied leave samples of E. camaldulensis (Leicach et al., 2010) and E. globulus (Silvestre et al., 1997) have come to identical conclusions and even reported that YL EOs tend to have higher amounts of $\mathrm{MH}$ such as $\alpha$ - and $\beta$-pinene, $\beta$-myrcene, and limonene, and lower concentrations of OM (1,8-cineole and $\alpha$-terpineol) than ML (Figure 2).

\section{Insecticidal activity assay}

The toxicity bioassay indicated that EOs and CIN solutions showed interesting insecticidal properties against of $T$. confusum adults (Table 2). The values of adult mortality expressed as percentage (\%) were significantly different compared with control $(\mathrm{P} \leq 0.05)$. Insecticidal effects increased according to exposure time and concentration.

At $30 \mathrm{~min}$ of observation and when applied concentration was $0.5 \mu \mathrm{L} \mathrm{cm}^{-2}$, no dead insects were 

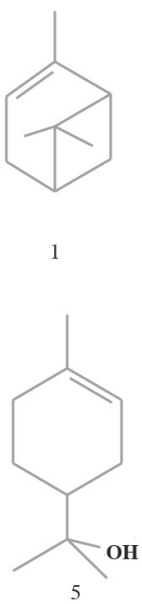

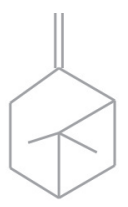

2

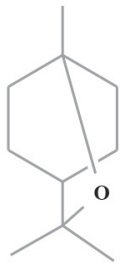

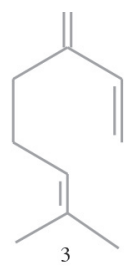
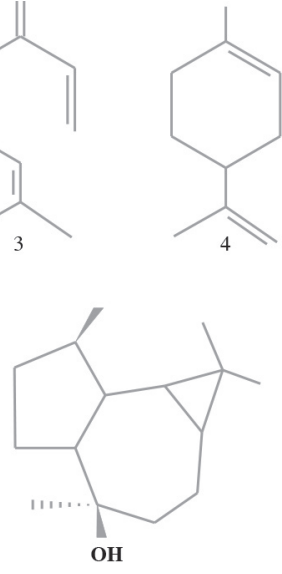

1: $\alpha$-Pinene, 2: $\beta$-pinene, 3: $\beta$-myrcene, 4: limonene, 5: $\alpha$-terpineol, 6 : 1,8-cineole, 7: globulol.

Figure 2. Terpene components in Eucalyptus globulus essential oil.

observed. When the doses achieved to $0.75 \mu \mathrm{L} \mathrm{cm}$, CIN solutions exhibited the most important significant differences between treatments and control, and also, at the highest concentrations $\left(1.25 \mu \mathrm{L} \mathrm{cm}^{-2}\right)$, the mortality achieved the highest values (90\%). Dilutions of ML EOs showed low adult insect mortalities $(<10 \%)$, only YLEOs at $1.25 \mu \mathrm{L} \mathrm{cm}^{-2}$ were much effective at $0.5 \mathrm{~h}(31.67 \%)$.

After $2 \mathrm{~h}$ at the lowest concentrations, YL EOs caused significantly higher mortality $(31.67 \%)$, meanwhile at $0.75 \mu \mathrm{L} \mathrm{cm}^{-2}$ ML EOs were the most effective (71.67\%). At $1.0 \mu \mathrm{L} \mathrm{cm} \mathrm{cm}^{-2}$ there were no significant differences between treatments, but YL EOs achieved mean values extremely close to $100 \%$ (98.33\%), whereas, at the higher doses $\left(1.25 \mu \mathrm{L} \mathrm{cm}^{-2}\right)$ no insects were alive.

Data showed that, at $4 \mathrm{~h}$ exposure, YL EOs applied at the lowest concentration $\left(0.5 \mu \mathrm{L} \mathrm{cm}^{-2}\right)$, exhibited the most effective toxicity (63.33\%), while a dose of $0.75 \mu \mathrm{L} \mathrm{cm}^{-2}$ was required to obtain $100 \%$ mortality. Meanwhile, ML and CIN solutions only exhibited the highest mortality percentage $(96.77 \%$ and $91.67 \%$, respectively) at a higher applied dose $\left(0.75 \mu \mathrm{L} \mathrm{cm}^{-2}\right)$. At the same time and 1.0 and $1.25 \mu \mathrm{L} \mathrm{cm}^{-2}$ applied concentrations, all treatments achieved $100 \%$ mortality.

It is important to observe that CIN solutions and MLEOs, at the lowest assayed concentrations did not achieve the highest percentage even when the bioassay was concluded $(12 \mathrm{~h})$, nevertheless, since at $0.75 \mu \mathrm{L} \mathrm{cm}^{-2}$, the rest of tested samples had reached almost to the maximum mortality at $6 \mathrm{~h}$. Many researches have reported on the effectiveness of CIN against stored-product insects (Alzogaray et al., 2011; Akhtar et al., 2012). In fact, Ebadollahi (2011) concluded that mortality of $T$. castaneum increased as the doses of $E$. globulus EOs and exposure times, and even CIN was largely responsible for these pesticidal properties. Also, these EOs showed to be ovicidal, larvicidal, pupicidal, antifeedant, and adulticidal against $T$. castaneum (Ebadollahi et al., 2010; Ebadollahi, 2011). Recent studies have shown that the toxicity of several constituents of EOs such as 1,8-cineole, caryophyllene, chavicol, citral, p-cymene, limonene, linalool, myrcene, $\alpha$-pinene, $\gamma$-terpinene, terpinen-4-ol, and $\alpha$-terpineol can be considered as main reasons of its insecticidal activities from Myrtaceae family on insect pests (Ebadollahi, 2013).

About the toxicity of eucalyptus oils, not much is known; but EOs are considered to reducing the harmful effect of conventional insecticides on humans and the environment. Regarding oil efficacy, our results suggested that YL EOs seemed to have remarkable insecticidal effects considering that mortality rate achieved $31.67 \%$ at the minor applied concentration $\left(0.5 \mu \mathrm{L} \mathrm{cm}^{-2}\right)$ in only $2 \mathrm{~h}$ of the beginning of the experiment, as well as, we observed the total adult insect mortality (100\%) only at 6 h. It must be remembered that mono- and sesquiterpene hydrocarbons were the dominant components at YL EOs, whereas ML ones were rich in oxygenated monoterpenes and sesquiterpenes. For plant species, a combination of terpenic derivatives may help to achieve protection against numerous predators. Several authors had concluded that the biological effects might be either the result of a synergism of all the molecules or could reflect only those of the main molecules. In that sense, for biological purposes, it could be more informative to

Table 2. Mortality percentage of Tribolium confusum treated with essential oils from young and mature leaves of Eucalyptus globulus at different exposure times.

\begin{tabular}{|c|c|c|c|c|c|c|}
\hline Treatment & $\mu \mathrm{L} \mathrm{cm}{ }^{-2}$ & $0.5 \mathrm{~h}$ & $2.0 \mathrm{~h}$ & $4.0 \mathrm{~h}$ & $6.0 \mathrm{~h}$ & $12 \mathrm{~h}$ \\
\hline Control & & $0.0 \mathrm{a}$ & $0.0 \mathrm{a}$ & $0.0 \mathrm{a}$ & $0.0 \mathrm{a}$ & $0.0 \mathrm{a}$ \\
\hline $\mathrm{CIN}$ & 0.50 & $0.0 \mathrm{a}$ & $5.00 \pm 1.22 \mathrm{ab}$ & $18.33 \pm 2.89 \mathrm{c}$ & $83.33 \pm 5.77 \mathrm{a}$ & $93.33 \pm 5.77 \mathrm{hij}$ \\
\hline ML & 0.50 & $0.0 \mathrm{a}$ & $0.0 \mathrm{a}$ & $31.67 \pm 2.89 \mathrm{~d}$ & $93.33 \pm 5.77 \mathrm{ijk}$ & $93.33 \pm 5.77 \mathrm{ijk}$ \\
\hline YL & 0.50 & $0.0 \mathrm{a}$ & $31.67 \pm 2.89 \mathrm{~d}$ & $63.33 \pm 5.77 f$ & $100.0 \mathrm{k}$ & $100.0 \mathrm{k}$ \\
\hline CIN & 0.75 & $48.33 \pm 2.89 \mathrm{e}$ & $46.67 \pm 5.77 \mathrm{e}$ & $91.67 \pm 2.89 \mathrm{ij}$ & $96.77 \pm 5.77 \mathrm{ijk}$ & $100.0 \mathrm{k}$ \\
\hline ML & 0.75 & $0.67 \pm 0.15 \mathrm{ab}$ & $71.67 \pm 2.89 \mathrm{~g}$ & $96.67 \pm 5.77 \mathrm{j}$ & $100.0 \mathrm{k}$ & $100.0 \mathrm{k}$ \\
\hline YL & 0.75 & $0.0 \mathrm{a}$ & $66.67 \pm 5.77 f$ & $100.0 \mathrm{k}$ & $100.0 \mathrm{k}$ & $100.0 \mathrm{k}$ \\
\hline $\mathrm{CIN}$ & 1.00 & $70.00 \pm 0.10 \mathrm{fg}$ & $96.67 \pm 5.77 \mathrm{ijk}$ & $100.0 \mathrm{k}$ & $100.0 \mathrm{k}$ & $100.0 \mathrm{k}$ \\
\hline ML & 1.00 & $4.67 \pm 0.58 \mathrm{ab}$ & $91.67 \pm 2.89 \mathrm{ij}$ & $100.0 \mathrm{k}$ & $100.0 \mathrm{k}$ & $100.0 \mathrm{k}$ \\
\hline YL & 1.00 & $0.0 \mathrm{a}$ & $98.33 \pm 2.8 \mathrm{jk}$ & $100.0 \mathrm{k}$ & $100.0 \mathrm{k}$ & $100.0 \mathrm{k}$ \\
\hline CIN & 1.25 & $90.00 \pm 0.00 \mathrm{hi}$ & $100.0 \mathrm{k}$ & $100.0 \mathrm{k}$ & $100.0 \mathrm{k}$ & $100.0 \mathrm{k}$ \\
\hline ML & 1.25 & $8.33 \pm 2.89 b$ & $100.0 \mathrm{k}$ & $100.0 \mathrm{k}$ & $100.0 \mathrm{k}$ & $100.0 \mathrm{k}$ \\
\hline YL & 1.25 & $31.67 \pm 2.89 \mathrm{~d}$ & $100.0 \mathrm{k}$ & $100.0 \mathrm{k}$ & $100.0 \mathrm{k}$ & $100.0 \mathrm{k}$ \\
\hline
\end{tabular}

CIN: 1,8-cineole, ML: mature leaves, YL: young leaves.

Adult mortality mean values $(\%) \pm \mathrm{SD}(\mathrm{n}=3)$. Data followed by different letters are significantly different according to Tukey test $(\mathrm{P} \leq 0.05)$. 
study the entire oil rather than some of its components because the concept of synergism seems to be important (Regnault-Roger et al., 2012; Ebadollahi et al., 2013).

\section{CONCLUSIONS}

The present results confirmed the importance of using young and mature essential oils of Eucalyptus globulus as a promising alternative for pest control of adults of Tribolium confusum. The contact effects, combined with low toxicity, rapid degradation in the environment and efficiency in pest control provides a simple, inexpensive, and environmental friendly alternative (non-polluting and lesser or no toxicological concerns). Young leaves essential oil, composed predominantly by monoterpene and sesquiterpene hydrocarbons, may be an excellent choice as natural insecticides considering their noticeable effects at low applied concentrations and short times of exposure.

\section{LITERATURE CITED}

Akhtar, Y., E. Pages, A. Stevens. R. Bradbury, C.A.G. da Camara, and M.B. Isman. 2012. Effect of chemical complexity of essential oils on feeding deterrence in larvae of the cabbage looper. Physiological Entomology 37:81-91.

Alzogaray, R.A., A. Lucia, E.N. Zerba, and H.M. Masuh. 2011. Insecticidal activity of essential oils from eleven Eucalyptus spp. and two hybrids: lethal and sublethal effects of their major components on Blattella germanica. Journal of Economic Entomology 104:595-600.

Batish, D.R., H.P. Singh, R.K. Kohli, and S. Kaur. 2008. Eucalyptus essential oil as a natural pesticide. Forest Ecology and Management 256:2166-2174

Boyer, S., H. Zhang, and G. Lempérière. 2012. A review of control methods and resistance mechanisms in stored-product insects. Bulletin of Entomological Research 102:213-229.

Brooker, M.I.H., and D.A. Kleinig. 2006. Field guide to Eucalypts: South-Eastern Australia, Vol. 1-3. Bloomings Books, Hawthorn, Victoria, Australia.

Caballero-Gallardo K., J. Olivero-Verbel, and E.E. Stashenko. 2012. Repellency and toxicity of essential oils from Cymbopogon martinii, Cymbopogon flexuosus and Lippia origanoides cultivated in Colombia against Tribolium castaneum. Journal of Stored Products Research 50:62-65.

Cimanga, K., K. Kambu, L. Tona, S. Apers, T. De Bruyne, N. Hermans, et al. 2002. Correlation between chemical composition and antibacterial activity of essential oils of some aromatic medicinal plants growing in the Democratic Republic of Congo. Journal of Ethnopharmacology 79:213-220.

Ebadollahi, A. 2011. Antifeedant activity of essential oils from Eucalyptus globulus Labill and Lavandula stoechas L. on Tribolium castaneum Herbst (Coleoptera: Tenebrionidae). Biharean Biologist 5:8-10.

Ebadollahi, A. 2013. Essential oils isolated from Myrtaceae family as natural insecticides. Annual Review \& Research in Biology 3(3): $148-175$

Ebadollahi, A., M. Rahimi-Nasrabadi, H. Batooli, and J. Geranmayeh. 2013. Evaluation of the insecticidal activities of three Eucalyptus species cultivated in Iran, against Hyphatria cunea druty (Lepidoptera: Arctiidae). Journal of Plant Protection Research 53:347-353.

Ebadollahi, A., M.H. Safaralizadeh, A.A. Pourmirza, and Y. Ghosta. 2010. Contact and fumigant toxicity of essential oils of Lavandula stoechas L. and Eucalyptus globulus Labill grown in Iran against Lasioderma serricorne F. Biharean Biologist 4:31-36.
El-Zemity, S., R. Hussien, F. Saher, and Z. Ahmed. 2006. Acaricidal activities of some essential oils and their monoterpenoidal constituents against house dust mite, Dermatophagoides pteronyssinus (Acari: Pyroglyphidae). Journal of Zhejiang University Science B 7:957-962.

Jovanovic, Z., M. Kostic, and P. Zorica. 2007. Grain-protective properties of herbal extracts against the bean weevil Acanthoscelides obtectus Say. Industrial Crops and Products 26:100-104.

Kazi, T.G., Arain M.B., Jamali, M.K., Jalbani, N., Afridi, H.I., Sarfraz, R.A., et al. 2008. Assessment of water quality of polluted lake using multivariate statistical techniques: A case study. Ecotoxicology and Environmental Safety. doi:10.1016/j. ecoenv.2008.02.024.

Lee, B.H., P.C. Annis, F. Tumaalii, and W.C. Choi. 2004. Fumigant toxicity of essential oils from the Myrtaceae family and 1,8-cineole against 3 major stored-grain insects. Journal of Stored Products Research 40:553-564.

Leicach, S.R., A.M. Garau, A.B. Guarnaschelli, M.A. YaberGrass, N.D. Sztarker, and A. Dato. 2010. Changes in Eucalyptus camaldulensis essential oil composition as response to drought preconditioning. Journal of Plant Interactions 5:205-210.

Li, H., J.L. Madden, and B.M. Potts. 1996. Variation in volatile leaf oils of the Tasmanian Eucalyptus species. II. Subgenus Symphyomyrtus. Biochemical Systemics and Ecology 24:547-569.

Lucia A., L.W. Juan, E.N. Zerba, L. Harrand, M. Marcó, and H.M. Masuh. 2012. Validation of models to estimate the fumigant and larvicidal activity of Eucalyptus essential oils against Aedes aegypti (Diptera: Culicidae). Parasitology Research 110(5):167-186

Manika, N., P. Mishra, N. Kumar, C.S. Chanotiya, and G.D. Bagchi. 2012. Effect of season on yield and composition of the essential oil of Eucalyptus citriodora Hook. leaf grown in sub-tropical conditions of North India. Journal of Medicinal Plants Research 6:2875-2879.

Mann, R.S., and P.E. Kaufman. 2012. Natural product pesticides: Their development, delivery and use against insect vectors. MiniReviews in Organic Chemistry 9:185-202.

McKiernan, A.B., M.J. Hovenden, T.J. Brodribba, B.M. Potts, N.W. Davies, and J.M. O'Reilly-Wapstra. 2014. Effect of limited water availability on foliar plant secondary metabolites of two Eucalyptus species. Environmental and Experimental Botany 105:55-64.

Mediouni Ben Jemâa, J., S. Haouel, and M.L. Khouja. 2013. Efficacy of Eucalyptus essential oils fumigant control against Ectomyelois ceratoniae (Lepidoptera: Pyralidae) under various space occupation conditions. Journal of Stored Products Research 53:67-71.

Pérez-Mendoza, J., P.W. Flinn, J.F. Campbell, D.W. Hagstrum, and J.E. Throne. 2004. Detection of stored-grain insect infestation in wheat transported in railroad hopper-cars. Journal of Economic Entomology 97:1474-1483.

Regnault-Roger, C., C. Vincent, and J.T. Arnason. 2012. Essential oils in insect control: low-risk products in a high-stakes world. Annual Review of Entomology 57:405-424.

Silvestre, A.J.D., J.A.S. Cavaleiro, B. Delmond, C. Filliatreb, and G. Bourgeois. 1997. Analysis of the variation of the essential oil composition of Eucalyptus globulus Labill. from Portugal using multivariate statistical analysis. Industrial Crops and Products 6:27-33.

Vinayachandra, S.R., and K.R. Chandrashekar. 2011. Larvicidal activities of Knema attenuata (Hook. f. \& Thomson) Warb. (Myristicaceae) extracts against Aedes albopictus Skuse and Anopheles stephensi Liston. Parasitology Research 109:1671-1676. 